\title{
EDITORIAL
}

\section{H63D genotying for hemochromatosis: Helper or hindrance?}

\author{
Paul C Adams MD FRCPC
}

$\mathrm{T}$ he introduction of genetic testing for hemochromatosis in 1996 was a major advance in the diagnosis. The C282Y mutation of the HFE gene is the major mutation and typical patients carry two copies of the C282Y mutation in this autosomal recessive disease. Homozygotes for the $\mathrm{C} 282 \mathrm{Y}$ mutation have been shown to exhibit conformational changes in the intracellular HFE protein (1), which then effects a cascade of other iron-related proteins eventually leading to a decreased and inappropriate serum hepcidin concentration, leading to increased intestinal iron absorption. The H63D mutation of the HFE gene has been considered to be a minor mutation because it does not show the same defect in cellular trafficking (2) and most patients with this mutation have normal iron studies. With the development of automated and high-throughput genetic testing, it has been common to test for $\mathrm{C} 282 \mathrm{Y}$ and $\mathrm{H} 63 \mathrm{D}$ mutations in all patients requesting HFE genotyping.

In the current issue of the Journal, Kelley et al (3) (pages 198-202) describe the results in a group of H63D homozygotes tested in Newfoundland and Labrador over a 10-year period (3). It was not a population-based study and $75 \%$ of patients had no evidence of iron overload. The reasons for testing in patients with normal iron tests is unknown, but it could be in the context of a family study. It is a referred population and there is a higher prevalence of HFE mutations than was apparent in the population-based HEIRS study (4) (Figure 1).

Have we saved any lives or improved quality of life by the identification of H63D homozygotes? Cirrhosis of the liver and hepatocellular carcinoma have not been described in these patients. The HEIRS study showed a very slight increase in self-reported arthritis in men (OR 1.28 [95\% CI 1.03 to 1.59]) and heart disease (OR 1.47 [95\% CI 1.04 to 2.07]) in women in H63D homozygotes. There was no increased self-reported liver disease (4). Has phlebotomy therapy in H63D homozygotes with modest elevations in serum ferritin levels improved their prognosis or quality of life? It has been difficult to prove these benefits even in C282Y homozygotes (5). Long-term survival has been shown to be similar in untreated H63D homozygotes compared with patients without HFE mutations (6). Many patients are alarmed by elevations in serum ferritin levels, and their fear and anxiety are fuelled by Internet misinformation. The key question is whether H63D testing is helpful in the assessment of a patient with an elevated ferritin level. How certain can we be that the H63D genotype is causing the elevated ferritin level with the knowledge that most cases have normal iron tests? We also know that our Canadian population is growing both in age and body weight, and fatty liver is likely the most common cause of an elevated ferritin level. The frequency of a serum ferritin level $>300 \mu \mathrm{g} / \mathrm{L}$ in Caucasian H63D homozygotes $(\mathrm{n}=1049)$ compared with participants without H63D mutations $(n=32,134)$ from the HEIRS study is shown in Figure 2. Because the percentage in each ferritin interval is very similar, attribution of the elevation in ferritin level to this genotype is difficult.

Could H63D genotyping be harmful to the patient? In the early days of genetic testing, there were many concerns about genetic discrimination by insurance companies. This was studied in great depth in the HEIRS study and there was not a single case in $>100,000$ participants (7). Of more concern were the effects of ambiguous genetic testing on the health-seeking behaviour of patients. Health care visits

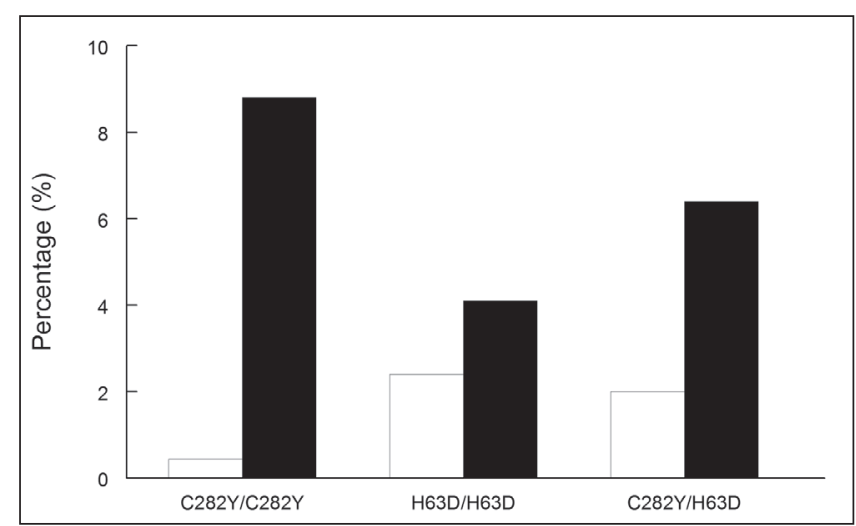

Figure 1) A comparison of the prevalence of HFE mutations in a referred population in Newfoundland and Labrador $(n=4138)$ (black bars) with 43,453 Caucasians from the population-based Hemochromatosis and Iron Overload Screening (HEIRS) study (open bars)

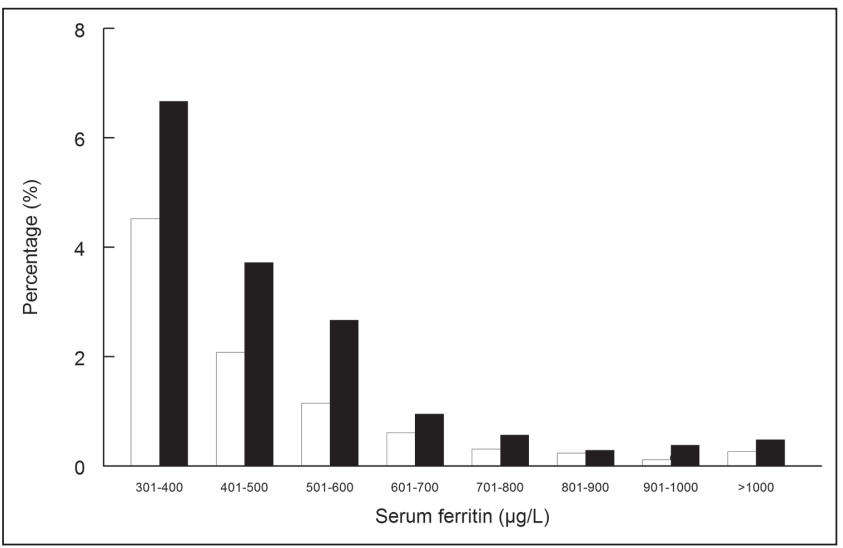

Figure 2) A comparison of the percentage of Hemochromatosis and Iron Overload Screening (HEIRS) study participants with an elevated serum ferritin level in H63D homozygotes $(n=1049)$ (black bars) and participants without $\mathrm{H} 63 \mathrm{D}$ or $\mathrm{C} 282 \mathrm{Y}$ mutations $(n=32,134)$ (open bars). All patients in this analysis were Caucasian

increase (8) and many patients attribute all of their somatic and mental health complaints to their newly discovered genotype. Many seasoned physicians have come to understand that 'less is more' with many diagnostic tests. Many patients still have the idea that 'more is more' and often are seeking direct-to-consumer genetic testing. Genetic testing for iron genes beyond HFE (hepcidin, hemojuvelin, ferroportin, transferrin receptor 2) testing is available direct to consumer at a cost of USD $\$ 1,500$ (invitae.com) but the interpretation of these results can be difficult. The development of iron gene chips that can test for many iron mutations at once will be a great challenge to genetic counsellors who are already not very familiar with iron overload disorders. 
In summary, the use of H63D genotyping has created a new subgroup of patients (H63D homozygotes, C282Y/H63D compound heterozygotes) that have rarely had any illness associated with iron overload. In many ways, these are genotypes searching for an illness. The movement to drop the H63D genetic test from routine HFE genotyping has not gained ground because of the low cost and the quest for new information (Box 1). In my own practice, I suggest voluntary blood donation two to three times per year for concerned patients, and rarely institute weekly phlebotomy. The health benefits appear to be minimal, other than increasing the blood donor pool, which should be encouraged.

\section{BOX 1}

Why perform H63D testing?

- Patient and physician would like to know why the serum ferritin is elevated.

- Other family members may have similar conditions.

- Phlebotomy treatment may be initiated because iron overload appears to be more likely.

Why not perform H63D testing?

- Most patients have normal iron stores.

- Ambiguous genetic testing results can cause an increase in health care visits.

- More genetic tests require more interpretation and counselling.

\section{REFERENCES}

1. Feder J, Tsuchihashi Z, Irrinki A, et al. The hemochromatosis founder mutation in HLA-H disrupts beta-2-microglobulin interaction and cell surface expression. J Biol Chem 1997;272:14025-8

2. Waheed A, Parkkila S, Zhou XY, et al. Hereditary hemochromatosis: Effects of $\mathrm{C} 282 \mathrm{Y}$ and H63D mutations on association with beta2-microglobulin, intracellular processing, and cell surface expression of the HFE protein in COS-7 cells. Proc Natl Acad Sci U S A 1997;94:12384-9.

3. Kelley M, Joshi N, Xie Y, Borgaonkar M. Iron overload is rare in patients homozygous for the H63D mutation. Can J Gastroenterol Hepatol 2014;28:198-202.

4. Adams PC, Reboussin DM, Barton JC, et al. Hemochromatosis and iron-overload screening in a racially diverse population. N Engl J Med 2005;352:1769-78.

5. Adams PC. The natural history of untreated HFE-related hemochromatosis. Acta Haematol 2009;122:134-9.

6. Pankow JS, Boerwinkle E, Adams PC, et al. HFE C282Y homozygotes have reduced low-density lipoprotein cholesterol: The Atherosclerosis Risk in Communities (ARIC) Study. Translational Research 2008;152:3-10.

7. Hall MA, Barton JC, Adams PC, et al. Genetic screening for iron overload: no evidence of discrimination at one year. J Fam Practice 2007;56:829-33.

8. Speechley M, Alter D, Guo H, Harrison H, Adams P. Effect of ambiguous hemochromatosis gene test results on physician utilization. Med Care 2012;50:394-8. 


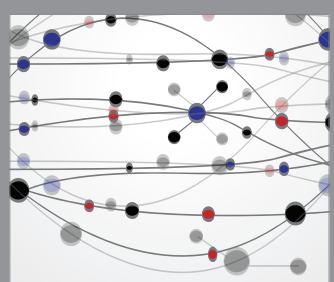

The Scientific World Journal
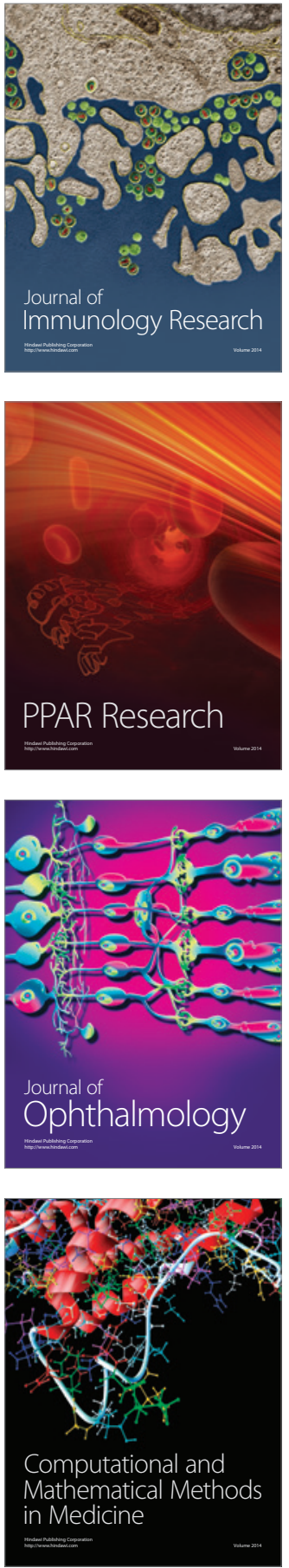

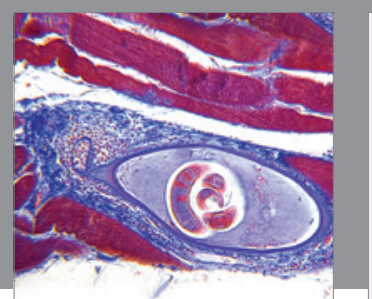

Gastroenterology Research and Practice

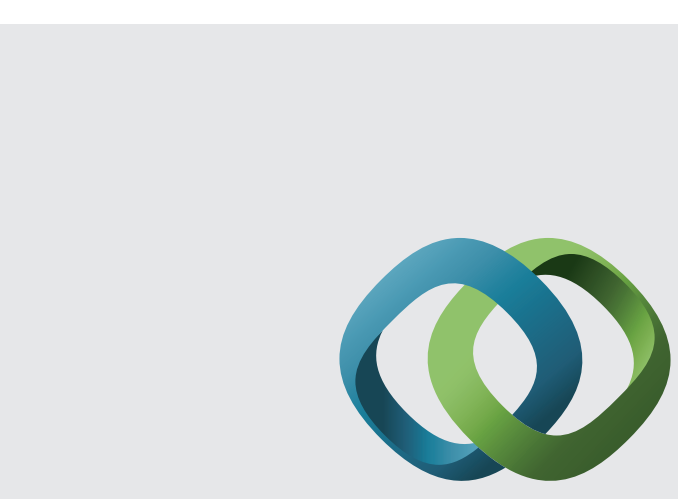

\section{Hindawi}

Submit your manuscripts at

http://www.hindawi.com
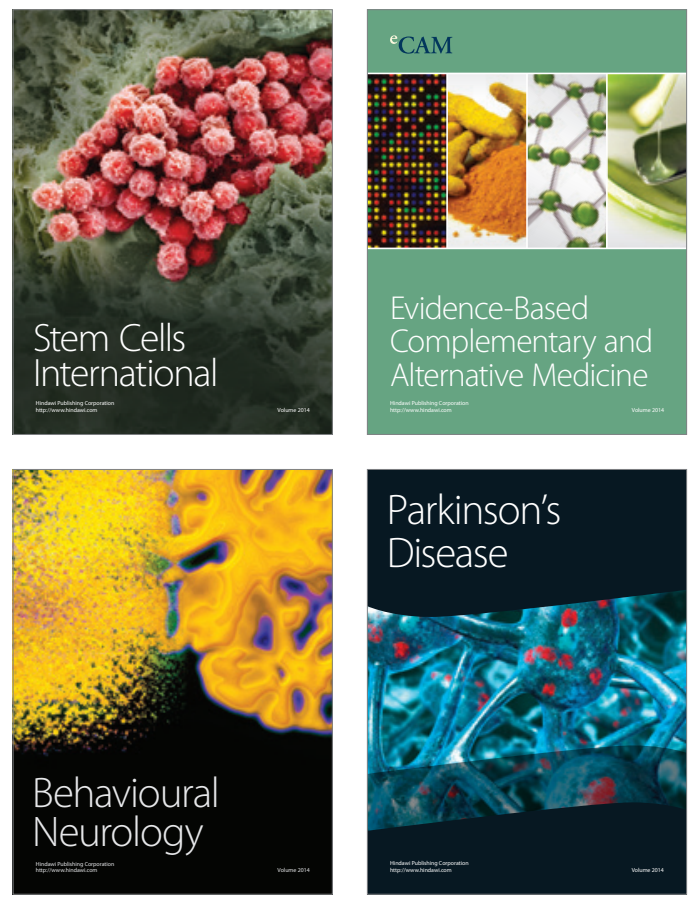
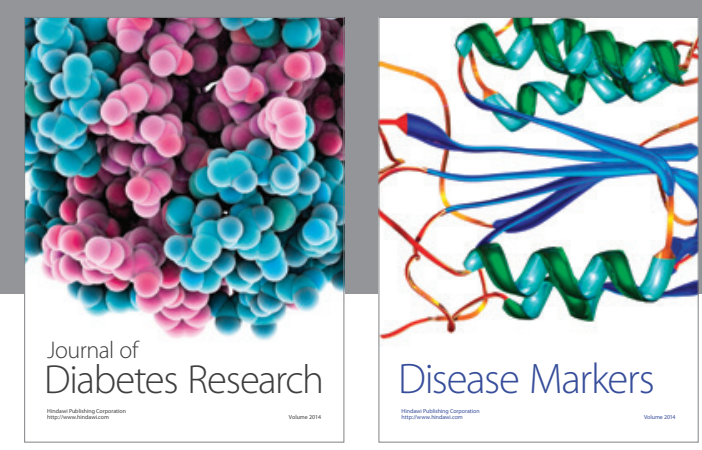

Disease Markers
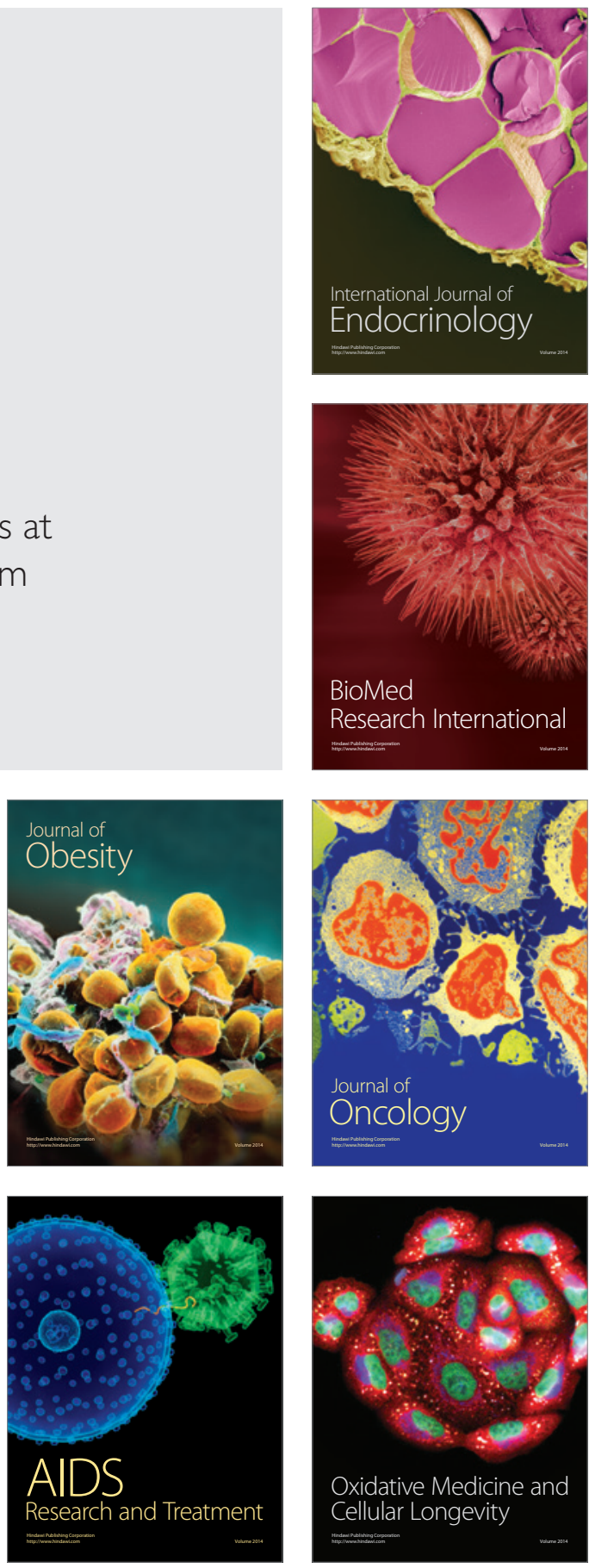